CORRECTION

https://doi.org/10.1038/s41586-018-0862-z

\title{
Author Correction: Widespread but heterogeneous responses of Andean forests to climate change
}

Belén Fadrique, Selene Báez, Álvaro Duque, Agustina Malizia, Cecilia Blundo, Julieta Carilla, Oriana Osinaga-Acosta,

Lucio Malizia, Miles Silman, William Farfán-Ríos,

Yadvinder Malhi, Kenneth R. Young, Cuesta C. Francisco,

Jurgen Homeier, Manuel Peralvo, Esteban Pinto,

Oswaldo Jadan, Nikolay Aguirre, Zhofre Aguirre \&

Kenneth J. Feeley

Correction to: Nature https://doi.org/10.1038/s41586-018-0715-9, published online 14 November 2018

In Fig. 2 of this Article, the positive part of the $y$ axis scale should read 0, 0.02, 0.04 instead of 0, 0.04, 0.02. The original Article has been corrected online. 